\title{
Comparative Study between Laparoscopic and Open Cholecystectomy: Complications and Management
}

\author{
Md. Rafiqul Islam¹, Md. Showkat Ali², S M Golam Azam³, Md. Ridwanul Islam
}

\section{Abstract}

Introduction: Laparoscopic cholecystectomy $(L C)$ is currently the most widely used surgical procedure for the treatment of gallstones. The aim of the study was to analyze and compare the postoperative results of patients undergoing laparoscopic cholecystectomy or open cholecystectomy $(O C)$ with regard to complications, recovery time and hospital stays. Materials and Methods: This is a retrospective study which was conducted at the General Hospital Khulna and some of the private Hospital in Khulna City from January 2015 to December 2019. This study which analyzed among 950 patients, 20-65 years old, diagnosed with gallstones undergoing LC or OC. We evaluated postoperative respiratory complications, surgical site infection, deep vein thrombosis, time to oral feeding and ambulation, use of antibiotics and duration of the postoperative period. Results: We analyzed 570(60\%) patients undergoing LC and 380 (40\%) OC. Most patients were female (55\%). Patients' comorbidities were hypertension (12.8\%), diabetes mellitus (4.5\%) and asthma (1.00\%). LC resulted in lower prevalence of postoperative complications (2.8\%) than OC (3.4\%). Postoperative hospitalization for 2-3 days was found in LC patients and 5-7 days in OC. Conclusion: Laparoscopic cholecystectomy showed higher benefits for patients with lower prevalence of postoperative complications, feeding earlier and shorter mean hospital stay compared with open cholecystectomy.

Keywords: Cholecystectomy, Laparotomy, Laparoscopy, Postoperative complications.

Number of Tables: 06; Number of References: 15; Number of Correspondence: 03.

*1. Corresponding Author:

Dr. Md. Rafiqul Islam FCPS (Surgery)

Senior Consultant

Department of Surgery

General Hospital, Khulna.

2. Dr. Md. Showkat Ali FCPS (Surgery)

Assistant Professor

Department of Surgery

Khulna Medical College, Khulna.

3. Dr. S M Golam Azam MS (Surgery)

Assistant Professor

Department of Surgery

Satkhira Medical College, Satkhira.

4. Dr. Md. Ridwanul Islam (MBBS)

HMO, Department of Surgery

General Hospital, Khulna.

\section{Introduction:}

Laparoscopic cholecystectomy has become the treatment of choice for chronic cholecystitis around the world. Laparoscopic cholecystectomy is still reported as having a higher complication rate for acute cholecystitis than for chronic cholecystitis, with a currently reported postoperative complication rate of about $9 \%$ to $17 \%$ in some published series ${ }^{1}$. The broad range of the complication and conversion rates should be kept in mind because they depend on variables such as patient age, emergency intervention, ASA classification, and the presence of acute inflammation (gangrene, empyema, or perforation) of the gallbladder $^{2}$. In the early stage of laparoscopic cholecystectomy, it was considered unsafe or technically difficult to perform laparoscopic cholecystectomy for acute cholecystitis ${ }^{3,4}$. With increasing experience in laparoscopic surgery, many surgical services have reported on the use of laparoscopic cholecystectomy for acute cholecystitis, suggesting that it is technically feasible but at the expense of a high conversion rate $^{5,6}$. and common bile duct lesions ${ }^{7}$. Routine use of the open procedure might enable more patients to have the operations during the acute phase because most surgeons are practiced in this approach. The impact of hospital stay and morbidity must also be taken into account. There is the expectation that open operation is associated with more pain and longer hospital stay ${ }^{8,9}$. In some trials successful laparoscopic cholecystectomy is associated with an earlier recovery and shorter hospital stay when compared with open cholecystectomy ${ }^{10}$. The aim of this study was to analyze and compare the perioperative results of patients undergoing laparoscopic and open cholecystectomy concerning to complications, hospital stay and cost.

\section{Materials and Methods:}

All patients having cholecystectomy at the General Hospital Khulna and some of the private Hospital in Khulna City from January 2015 to December 2019 were retrospectively registered in the study. Most of the operations were performed by consultants of surgery, but residents participated in surgery under supervision. Patients were eligible to participate in the trial comparing conventional open cholecystectomy and laparoscopic cholecystectomy according to exclusion and inclusion criteria.

We analyzed 950 patients, aged 20-65 years, diagnosed with gallstone 
disease randomly assigned to laparoscopic cholecystectomy or open cholecystectomy. Excluded were those with confirmed choledocholithiasis and underwent concomitant surgeries, pregnant women and patients with liver cirrhosis or malignant tumors. Demographic data such as age, sex, emergency or elective procedure, surgical risk (ASA score), duration of surgery, use of prophylactic heparin, Intercurrent diseases and use of prophylactic antibiotics were computed. Respiratory complications (pneumonia, bronchopneumonia, pleural effusion, pulmonary embolism), surgical site infections urinary infections, deep vein thrombosis and other complications were recorded from the immediate postoperative period until the time of hospital discharge. We evaluated the time to oral feeding and ambulation, length of postoperative hospital stay and the clinical conditions at the time of discharge.

\section{Results:}

Of the 950 patients, $570(60 \%)$ underwent laparoscopic surgery and 380 (40\%), open cholecystectomy, distributed by gender and age as shown in Table I. We found a relationship of man to women.

Table-I: Prevalence of age and sex.

\begin{tabular}{lccccc}
\hline $\begin{array}{l}\text { Type of } \\
\text { cholecystectomy }\end{array}$ & Age & Male & Female & M:F Ratio & Total \\
\hline Laparoscopic & $45 \pm 11$ & 250 & 320 & $1: 1.28$ & 570 \\
\hline Open & $47 \pm 10$ & 175 & 205 & $1: 1.17$ & 380 \\
\hline Total & $46 \pm 10.5$ & 425 & 525 & $1: 1.22$ & 950 \\
\hline
\end{tabular}

Most of the patients had co-morbidities such as hypertension, asthma and diabetes mellitus (Table II).

Table-II:Intercurrent illness (co-morbidities).

\begin{tabular}{l|c|c|c}
\hline Diseases & $\begin{array}{l}\text { Laparoscopic } \\
\text { Cholecystectomy }\end{array}$ & $\begin{array}{c}\text { Open } \\
\text { Cholecystectomy }\end{array}$ & Total \\
\hline Hypertension & 67 & 55 & $122(12.8 \%)$ \\
\hline Diabetes & 25 & 18 & $43(4.5 \%)$ \\
\hline Asthma & 6 & 4 & $10(01 \%)$ \\
\hline Nontoxic goiter & 1 & 0 & 1 \\
\hline Lung complications & 4 & 2 & 6 \\
\hline
\end{tabular}

There was no difference in median time to onset of postoperative oral feeding. It was earlier in laparoscopic cholecystectomy, where $540(94.7 \%)$ patients received oral diet introduced in the first 12 hours, while in open surgery, the oral intake was introduced in 319 (84\%) patients after 24 hours (Table III).

Table-III:Time for the beginning of postoperative oral feeding.

\begin{tabular}{l|l|l|l|l|l}
\hline Surgery & $\mathbf{5 - 6} \mathbf{h}$ & $\mathbf{1 2 h}$ & $\mathbf{2 4 h}$ & $\mathbf{4 8 h}$ & $\mathbf{7 2 h}$ \\
\hline $\begin{array}{l}\text { Laparoscopic } \\
\text { Cholecystectomy }\end{array}$ & 20 & 540 & 6 & 4 & 0 \\
\hline $\begin{array}{l}\text { Open } \\
\text { Cholecystectomy }\end{array}$ & 0 & 32 & 319 & 25 & 4 \\
\hline
\end{tabular}

Mean operative time in laparoscopic surgery was 30 to 60 minutes in most 310 patients $(54.3 \%)$. Open surgery lasting 30 to 60 minutes were performed in 140 patients $(36.8 \%)$, significantly less when compared with laparoscopic surgery. We performed 252 (44.2\%) laparoscopic cholecystectomy in the time interval 61-120 minutes, significantly less than $220(57 \%)$ open cholecystectomy in the same time interval (61-180 minutes) (Table IV).

Table-IV: Operative times (minutes).

\begin{tabular}{l|c|c|c|c|c}
\hline Operations & $\mathbf{6 0 - 9 0}$ & $\mathbf{9 1 - 1 2 0}$ & $\mathbf{1 2 1} \mathbf{- 1 8 0}$ & $>\mathbf{1 8 1}$ & Total \\
\hline $\begin{array}{l}\text { Laparoscopic } \\
\text { Cholecystectomy }\end{array}$ & 310 & 252 & 6 & 2 & 570 \\
\hline $\begin{array}{l}\text { Open } \\
\text { Cholecystectomy }\end{array}$ & 140 & 220 & 14 & 6 & 380 \\
\hline
\end{tabular}

Most of the patients with Laparoscopic Cholecystectomy leave hospital within 2-3 days. Patients with open Cholecystectomy leave hospital on 5- 7 days.

Table-V: Hospital stay (days).

\begin{tabular}{l|c|c|c|c|c}
\hline Operations & $\mathbf{1 - 2}$ & $\mathbf{2 - 3}$ & $\mathbf{3 - 4}$ & $\mathbf{5 - 6}$ & $\mathbf{6 - 7}$ \\
\hline $\begin{array}{l}\text { Laparoscopic } \\
\text { Cholecystectomy }\end{array}$ & 5 & 503 & 40 & 22 & 0 \\
\hline $\begin{array}{l}\text { Open } \\
\text { Cholecystectomy }\end{array}$ & 0 & 0 & 4 & 326 & 50 \\
\hline
\end{tabular}

Operative complications resulting from laparoscopic procedure occurred in $16(2.8 \%)$ patients, 6 patients with wound infection. The remaining 10 patients who had complications were affected by bile duct injury, bile peritoneum, port site haemorrhage, deep vein thrombosis, subcutaneous emphysema. Operative complications resulting from open procedure occurred in $13(3.4 \%)$ patients. The surgical site infection was the most frequent complication, diagnosed in 8 patients, followed by urinary tract infection in 2 patients.

Table-VI: Post operative complications observed in patients undergoing laparoscopic and open cholecystectomy.

\begin{tabular}{lcc}
\hline Complications & $\begin{array}{c}\text { Laparoscopic } \\
\text { Cholecystectomy }\end{array}$ & $\begin{array}{c}\text { Open } \\
\text { Cholecystectomy }\end{array}$ \\
\hline Wound infection & 6 & 8 \\
\hline Urinary infection & 1 & 2 \\
\hline Bile duct injury & 2 & 0 \\
\hline Internal haemorrhage & 1 & 0 \\
\hline Port site haemorrhage & 2 & 0 \\
\hline Deep vein thrombosis & 1 & 1 \\
\hline Respiratory infection & 2 & 2 \\
\hline Subcutaneous emphysema & 1 & 0 \\
\hline Total & $\mathbf{1 6 ( 2 . 8 \% )}$ & $\mathbf{1 3 ( 3 . 4 \% )}$ \\
\hline
\end{tabular}

\section{Discussion:}

Laparoscopic cholecystectomy has largely supplanted the open technique. This is because of the benefits of LC in respect of duration of postoperative hospital stay, shorter time of operative procedure, early recovery, less complications etc. In the present study, the duration of postoperative hospital stay for laparoscopic surgery was from 2 to 3 days in 503 patients $(88.25 \%)$, and in open cholecystectomy was $5-6$ days in 326 patients $(85.58 \%)$. The hospital stay in OC is much more than LC. Other studies showed the mean postoperative stay for an open cholecystectomy has been 8 days compared with the 3 days recorded for laparoscopy ${ }^{11}$. The mean operating time for an open cholecystectomy has been given as 90 minutes, as opposed to 95 minutes for the laparoscopic procedure ${ }^{12}$. These data contrast with our results of 90 minutes and 75 minutes, respectively. Both perioperative and postoperative complications are thoroughly dealt with in most studies that have compared open and laparoscopic cholecystectomy ${ }^{12,13}$. Usually, complications are classified as bile duct injury, vascular, bowel injury, residual stones, wound or urinary tract 
infections, urinary retention, and ileus ${ }^{14}$. Bile duct injuries has been more common after laparoscopic than open cholecystectomy ${ }^{15}$. In the present study we had two cases of bile duct injury. The patients were reoperated and the injury was successfully treated.

\section{Conclusion:}

Laparoscopic cholecystectomy offers the greatest benefits to patients; it was associated with a lower rate of postoperative complications, feeding earlier and shorter average hospital stay than open cholecystectomy. The operative procedures performed in government hospital were free of cost. The cost of laparoscopic cholecystectomy was about the same as those of the open conventional procedure in private hospital. The difference in cost was attributable to the considerably shorter postoperative stay after the laparoscopic procedure.

\section{Conflict of Interest: None.}

\section{Acknowledgement:}

The authors gratefully acknowledge Dr. Gazi Shafiqur Rahman MBBS for helping with valuable suggestions and documentation.

\section{References:}

1. Navez B, Mutter D, Russier Y. Safety of laparoscopic approach for acute cholecystitis: retrospective study of 609 cases. World J Surg. 2001;25:1352-6.

https://doi.org/10.1007/s00268-001-0122-4

PMid:11596902

2. Schafer M, Krähenbühl L, Büchler MW. Predictive factors for the type of surgery in acute cholecystitis. Am J Surg. 2001;182: 291-7.

https://doi.org/10.1016/S0002-9610(01)00702-4

3. Rai R, Sinha A, Rai S. Randomized clinical trial of open versus laparoscopic cholecystectomy in the treatment of acute cholecystitis. Br J Surg. 2005; 92:44-49.

https://doi.org/10.1002/bjs.4836

PMid:15584058

4. Nuzzo G, Giuliante F, Persiani R.The risk of biliary ductal injury during laparoscopic cholecystectomy. J Chir (Paris).2004;141:343-53.

https://doi.org/10.1016/S0021-7697(04)95358-6

5. Johansson M, Thune A, Nelvin L, Stiernstam M, Westman B, Lundell L. Randomized clinical trial of open versus laparoscopic cholecystectomy in the treatment of acute cholecystitis. Br J Surg. 2005;92:44-9.

https://doi.org/10.1002/bjs.4836

PMid:15584058

6. Asoglu O, Ozmen V, Karanlik H, Igci A, Kecer M, Parlak M,et al. Does the complication rate increase in laparoscopic cholecystectomy for acute cholecystitis? J LaparoendoscAdvSurg Tech. A 2004;14:81-6.

https://doi.org/10.1089/109264204322973844

PMid:15107216

7. Johansson M, Thune A, Blomqvist A, Nelvin L, Lundell L. Management of acute cholecystitis in the laparoscopic era: results of a prospective, randomized clinical trial. J Gastrointest Surg. 2003;7:642-5.

https://doi.org/10.1016/S1091-255X(03)00065-9

8. Chau CH, Tang CN, Siu WT, Ha JP, Li MK. Laparoscopic cholecystectomy versus open cholecystectomy in elderly patients with acute cholecystitis: retrospective study. Hong Kong Med J. 2002;8:394-9.

9. Pessaux P, Regenet N, Tuech JJ, Rouge C, Bergamaschi R, Arnaud JP. A prospective comparative study in the elderly with acute cholecystitis. SurgLaparoscEndoscPercutan Tech. 2001;11:252-5.

https://doi.org/10.1097/00129689-200108000-00005

PMid: 11525370

10. Glavic Z, Begic L, Simlesa D, Rukavina A. Treatment of acute cholecystitis. A comparison of open vs laparoscopic cholecystectomy. SurgEndosc. 2001;15:398-401.

https://doi.org/10.1007/s004640000333

PMid:11395823

11. Nilsson E, Ros A, Rahmqvist M, Bäckman K, Carlsson P. Cholecystectomy: costs and health-related quality of life: a comparison of two techniques. Int $\mathbf{J}$ Qual Health Care. 2004; 16:473-82.

https://doi.org/10.1093/intqhc/mzh077

PMid: 15557357

12. Kesteloot K, Penninckx F. The costs and effects of open versus laparoscopic cholecystectomies.Health Economics. 1993; 2: 303-312.

https://doi.org/10.1002/hec.4730020403

PMid:8142992

13. De Pouvourville G, Ribet-Reinhart N, Fendrick M, Houry S, Testas P, Huguier M. A prospective comparison of costs and morbidity of laparoscopic versus open cholecystectomy.Hepatogastroenterology. 1997; 44: 35-9.

14. Ponsky JL. Complications of laparoscopic cholecystectomy. Am J Surg. 1991; 161: 393-395.

https://doi.org/10.1016/0002-9610(91)90605-D

15. Deziel DJ, Millikan KW, Economou SG, Doolas A, Ko S-T, Airan MC. Complications of laparoscopic cholecystectomy: a national survey of 4,292 hospitals and an analysis of 77,604 cases. Am J Surg. 1993; 165: 9-14.

https://doi.org/10.1016/S0002-9610(05)80397-6 